\title{
MAPEAMENTO DAS ÁREAS DE PRESERVAÇÃO PERMANENTE E IDENTIFICAÇÃO DOS CONFLITOS DE USO DA TERRA NA SUB-BACIA HIDROGRÁFICA DO RIO CAMAPUÃ/BRUMADO ${ }^{1}$
}

\author{
Andrea Brandão Gonçalves ${ }^{2}$, Gustavo Eduardo Marcatti ${ }^{3}$, Carlos Antonio Alvares Soares Ribeiro ${ }^{4}$, \\ Vicente Paulo Soares ${ }^{4}$, João Augusto Alves Meira Neto ${ }^{5}$, Helio Garcia Leite ${ }^{4}$, José Marinaldo Gleriani ${ }^{4}$ e \\ Vanessa Mendes Lana ${ }^{6}$
}

\begin{abstract}
RESUMO - O objetivo deste trabalho foi mapear e quantificar as áreas de preservação permanente (APPs) de acordo com a Resolução nº 303/02 do CONAMA para, então, com base no mapa de uso da terra e cobertura vegetal, identificar e quantificar os eventuais conflitos de uso da terra, com vistas a nortear o cumprimento da lei e promover o uso adequado dos recursos da sub-bacia hidrográfica do rio Camapuã/Brumado, MG. Utilizaram-se uma imagem digital do sensor ETM+/LANDSAT 7, bases cartográficas planialtimétricas do IBGE para a área de estudo, e os softwares Anudem 5.2, Erdas Imagine 9.2 e ArcGIS 9.3. As APPs ocuparam 63.095 ha, representando 57,0\% da área total da sub-bacia (110.711,9 ha). Com relação às categorias de APPs, o terço superior da bacia, ao longo das linhas de cumeada, correspondeu a 52,6\% dos 63.095 ha; as zonas de proteção às margens dos cursos d’água, a 31,4\%; a proteção das nascentes, a $15,6 \%$; e as encostas com declividade superior a $45^{\circ}$ e o terço superior de morros totalizaram $0,4 \%$. As áreas de terço superior da bacia, ao longo das linhas de cumeada, foram as mais desrespeitadas $(55,9 \%)$, seguidas das margens de curso d'água (23,12\%), proteção de nascentes $(20,83 \%)$, encostas com declividade superior a $45^{\circ}(0,3 \%)$ e terço superior de morros $(0,1 \%)$. Foram identificados $21.939,3$ ha de APPs sendo explorados por atividades agropecuárias, o que representa 34,8\% do total de APPs. Entretanto, constatou-se que 30.734,3 ha dos 47.616,9 ha situados fora das áreas de APP, i.e., 64,5\% das áreas legalmente passíveis de conversão de uso da terra, estavam cobertos por vegetação nativa. Encontraram-se sólidas evidências de que a falta de conhecimento a respeito da espacialização das APPs dentro da propriedade é a principal causa do descumprimento da lei. A delimitação e espacialização das APPs pelo geoprocessamento viabilizam a aplicação da legislação florestal, contribuindo notoriamente para minimizar os conflitos de uso da terra e evitar a degradação dos remanescentes florestais pela formação de corredores ecológicos naturais que mitiguem os efeitos deletérios da fragmentação de habitats.
\end{abstract}

Palavras-chave: Legislação florestal, Uso da terra e Código florestal brasileiro.

\section{MAPPING PERMANENT PRESERVATION AREAS AND LAND USE CONFLICTS IDENTIFICATION AT THE CAMAPUÃ/BRUMADO RIVER BASIN}

\begin{abstract}
The major bottleneck towards environmental compliance and law enforcement in Brazil is the lack of up-to-date maps accurately depicting the boundaries of protected areas as set by the Forest Code. A detailed study carried out over the Camapuã/Brumado watersheds, based on CONAMA's Act no 303/2002, was meant to identify and quantify eventual land use legal conflicts. An ETM+/LANDSAT 7 digital image, topographic datasets and the softwares Anudem 5.2, Erdas Imagine 9.2 and ArcGIS 9.3 were used to create visual depictions of both permanent preservation areas (PPA) and land use/land cover. PPAs corresponded to 57,0\% of the total area of the watersheds $(110.711,9$ ha $)$, being 52,6\% located on the upper third of hills
\end{abstract}

\footnotetext{
${ }^{1}$ Recebido em 19.04.2010 e aceito para publicação em 28.05.2012.

${ }^{2}$ Secretaria de Meio Ambiente do Estado de São Paulo. E-mail: <andrea_vix@yahoo.com.br>.

${ }^{3}$ Programa de Pós-Graduação em Ciência Florestal pela Universidade Federal de Viçosa, UFV. E-mail: <gustavomarcatti@ gmail.com>.

${ }^{4}$ Departamento de Engenharia Florestal, Universidade Federal de Viçosa, UFV. E-mail: <cribeiro@ ufv.br>, <vicente@ufv.br>, $<$ hgleite@gmail.com>e<gleriani@ufv.br>.

${ }^{5}$ Departamento de Biologia Vegetal, Universidade Federal de Viçosa, UFV. E-mail: <j.meira@ufv.br>.

${ }^{6}$ Escola Técnica de Viçosa, ETEV. E-mail: <vmendeslana@gmail.com>.
} 
along the watersheds' divides, 31,4\% on riparian zones, 15,6\% around springs and their drainage areas and $0,4 \%$ combining the areas situated on hillsides with slopes greater than $45^{\circ}$ and on the upper third of hills. On one hand, farming activities were identified on $22.000 \mathrm{ha}$, representing $35 \%$ of the protected areas. On the other hand, $31.000 \mathrm{ha}$, accounting for $65 \%$ of the total area that could be legally converted to agricultural lands, were still preserved by native vegetation. These empirical evidences corroborate the hypothesis that the lack of suitable maps showing the limits of protected areas - a responsibility of Brazilian government - forces farmers to operate on the margin of the law, being the primary cause of illegal land use.

Keywords: Forest legislation, Land use, Brazilian and Forest Code.

\section{INTRODUÇÃO}

As Áreas de Preservação Permanente (APPs), definidas pelo Código Florestal Brasileiro e posteriormente consideradas como reservas ecológicas pela Lei n ${ }^{\circ} 6.938$, de 31 de agosto de 1981, são assim caracterizadas por apresentarem, via de regra, grande fragilidade quanto a possíveis impactos ambientais. No entanto, seu histórico revela um contínuo desrespeito legal consolidado no uso indevido dos seus recursos pelos produtores rurais, que desconhecem e, ou, possuem dificuldade em interpretar as normas que caracterizam e regulam o uso dessas áreas (CALABRIA, 2004). Os órgãos florestais com poder de fiscalização muitas vezes se mostram incapazes de impor o cumprimento da legislação florestal brasileira, combinando despreparo técnico com infraestrutura inadequada, o que agrava a situação descrita.

A partir dessa constatação, como alternativa viável e essencial para a conquista de práticas adequadas, destaca-se como grande aliado o planejamento ambiental, constituído por um processo flexível e dinâmico, baseado na descrição detalhada dos seus aspectos físicos, biológicos e socioeconômicos da área de estudo (PIRES et al., 1998). Contudo, a falta de informações confiáveis e atualizadas sobre as condições do meio ambiente local tem representado um dos maiores entraves para o planejamento das ações do poder público e demais segmentos da sociedade, além de favorecer a degradação dos diferentes ecossistemas, devido ao desconhecimento e uso de estratégias inadequadas de manejo do solo, das águas e das florestas (TONIAL et al., 2000). O uso inapropriado das terras, com sério comprometimento da sua capacidade produtiva, é um tema atual e relevante, uma vez que muitas propriedades rurais apresentam algum tipo de uso conflitivo do solo. As soluções para os problemas decorrentes de um modelo predatório de uso e ocupação da terra são urgentes e merecem toda a atenção que vêm recebendo.
Diante do exposto, a identificação e delimitação de APPs urgem o aprimoramento das técnicas e sistemas empregados. O uso de geotecnologias, entre as quais o Sensoriamento Remoto, que possibilita a aquisição e produção de informações cartográficas (e.g., programas de imageamento orbital global Alos, Aster, Cartosat, CBERS, Envisat, GeoEye, Ikonos, IRS, Landsat, Modis, Prism, Spot, Terrasar) sobre o uso atual da terra, e os Sistemas de Informações Geográficas, instrumentos consagrados de análise e modelagem do espaço geográfico, mostraram-se bastante eficientes para a delimitação de APPs. Em um país de dimensões continentais como o Brasil, é imprescindível a representação e caracterização dessas áreas, para que se possa promover o fiel cumprimento da lei e a implementação de ações voltadas para a preservação e manutenção desses ambientes naturais.

Este estudo teve como objetivos: i) o mapeamento das áreas de preservação permanente da sub-bacia hidrográfica do rio Camapuã/Brumado, MG, em estrita consonância com o Código Florestal vigente à época da elaboração deste trabalho; e ii) a identificação e quantificação de eventuais conflitos de uso da terra, a partir da classificação temática da imagem digital do sensor ETM+/LANDSAT 7.

Este trabalho integra o Projeto de Revitalização da Bacia de Contribuição da Hidrelétrica de Três Marias. A área analisada engloba as cabeceiras da bacia do rio Paraopeba, constituindo importante região para a preservação das nascentes e, consequentemente, para a manutenção da qualidade e quantidade de água da bacia.

\section{Caracterização da área de estudo}

A sub-bacia hidrográfica do rio Camapuã/Brumado, com uma área de 110.711,9 ha, pertence à região do Alto Paraopeba, Minas Gerais, situando-se entre as coordenadas UTM 7.732.808 m e 7.683.662 m na direção 
N-S e 611.383 m e 572.329 m na direção L-O (Figura 1). Segundo a classificação de Köppen, a região caracteriza-se por um clima mesotérmico (VALLOUREC;SUMITOMO TUBOS DO BRASIL, 2007), verão chuvoso de outubro a março e estação seca de abril a setembro, com precipitação média anual de 1.236 mm (SILVA JÚNIOR, 1984). A vegetação é típica de uma zona de transição entre os biomas Mata Atlântica e Cerrado, cujos remanescentes se encontram em diferentes estágios sucessionais (IBGE, 2004).

Por situar-se na zona de influência do Quadrilátero Ferrífero, sofreu fortes interferências antrópicas devido à sua vocação para atividades mineradoras e industriais.

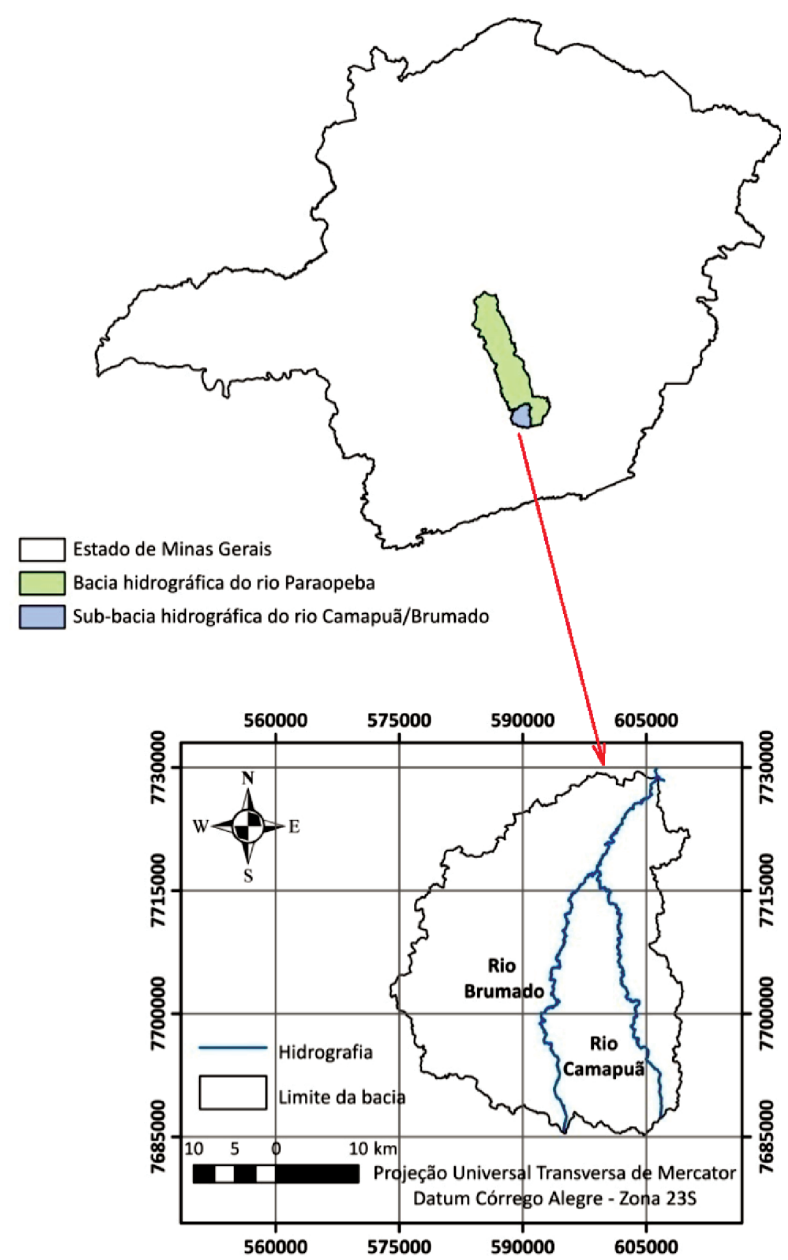

Figura 1 -Localização da sub-bacia hidrográfica do rio Camapuã/ Brumado, Minas Gerais.

Figure 1 -- Location of Camapuã/Brumado watershed in the state of Minas Gerais, Brasil.
Esse fato, aliado às atividades agropecuárias (principalmente a pecuária extensiva), ao uso indiscriminado do fogo e à retirada ilegal de madeira, contribui consideravelmente para a perturbação dos fragmentos de vegetação remanescentes (OLIVEIRA FILHO et al., 1994). Segundo o relatório de qualidade das águas de Minas Gerais (IGAM, 2009), a ocupação e uso inadequados do solo da região refletiram, entre outros aspectos, na contaminação dos corpos d’água por coliformes fecais termotolerantes (devido ao inadequado sistema de tratamento de esgoto), contaminação por chumbo, ferro e manganês (devido às incorretas práticas agrícolas que aumentam a presença natural desses elementos nas águas), turbidez e sólidos totais em suspensão (decorrentes dos processos de erosão e lixiviação da superfície dos solos desprotegidos).

Localizada numa faixa próxima ao bordo sudoeste das escarpas abruptas que delimitam o Quadrilátero Ferrífero, na região do Planalto Dissecado (centro-sul de Minas Gerais), a sub-bacia do rio Camapuã/Brumado apresenta relevo suave-ondulado, com morros de topos arredondados e vertentes predominantemente convexas (VALLOUREC; SUMITOMOTUBOS DOBRASIL, 2007). Dessa forma, possui vocação intrínseca para alocação de boa proporção de regiões do seu relevo em áreas consideradas de preservação permanente, conforme determinações dos artigos 2ㅇ e 3o da Resolução no 303/ 02 do CONAMA.

\section{MATERIAL E MÉTODOS}

\section{Base de dados, equipamentos e softwares utilizados}

Utilizou-se uma imagem digital da área de estudo proveniente do sensor ETM+/LANDSAT 7, com resolução espacial de $30 \mathrm{~m}$, datada de 2002. Para a geração do modelo digital de elevação hidrograficamente condicionado (MDEHC), utilizaram-se as bases cartográficas topográficas digitais, vetorizadas pelo IBGE a partir das suas cartas analógicas na escala de 1:50.000, contendo hidrografia e curvas de nível com equidistância vertical de $20 \mathrm{~m}$. O tratamento e análise dos dados foram realizados com o uso dos softwares Anudem versão 5.2, Erdas Imagine versão 9.2 e ArcGIS versão 9.3, destacando-se deste último os módulos ArcMap e ArcInfo Workstation (ESRI, 2008).

Para a geração do mapa de uso e ocupação da terra, realizou-se uma classificação supervisionada da imagem LANDSAT 7, usando as bandas 2 (0,52-0,60

Revista Árvore, Viçosa-MG, v.36, n.4, p.759-766, 2012 
$\mu \mathrm{m}), 3(0,63-0,69 \mu \mathrm{m})$ e $4(0,76-0,90 \mu \mathrm{m})$ e o algoritmo de classificação da máxima verossimilhança. Com a finalidade de verificar a confiabilidade do mapa gerado, efetuou-se a avaliação da sua exatidão, por meio do índice Kappa. Este índice é uma medida da diferença entre a concordância dos dados de referência e a classificação automática e a probabilidade de concordância entre os dados de referência e a classificação aleatória. Tomando por base a matriz de confusão apresentada na Tabela 1, o índice Kappa é obtido mediante a aplicação da seguinte fórmula (LILLESAND; KIEFER, 2001):

$$
K=\frac{n\left(\sum_{i=1}^{c} x_{i i}\right)-\mathrm{E}_{i=1}^{c}\left(x_{i+} x_{+i}\right)}{n^{2}-\sum_{i=1}^{c}\left(x_{i+} x_{+i}\right)}
$$

em que:

$n=$ número total de pixels amostrados;

$x_{i i}=$ número de pixels da i-ésima classe classificados corretamente;

$\mathrm{c}=$ número total de classes;

$x_{i+}=$ número de pixels selecionados (amostras) para comporem a i-ésima classe (linha); e

$x_{+i}=$ número de pixels classificados como pertencentes à i-ésima classe (total da coluna).

\section{Desenvolvimento do modelo digital de elevação hidrograficamente condicionado}

Um modelo digital de elevação hidrograficamente condicionado (MDEHC) foi produzido para a região de estudo, utilizando-se os dados digitais de altimetria - curvas de nível e pontos cotados - extraídos da base cartográfica planialtimétrica do IBGE. Adotou-se uma margem de $10 \mathrm{~km}$ em torno da malha hidrográfica vetorial para garantir a correta representação dos divisores de água da sub-bacia analisada. Utilizando-se os recursos

Tabela 1 - Matriz de confusão.

Table 1 - Error matrix.

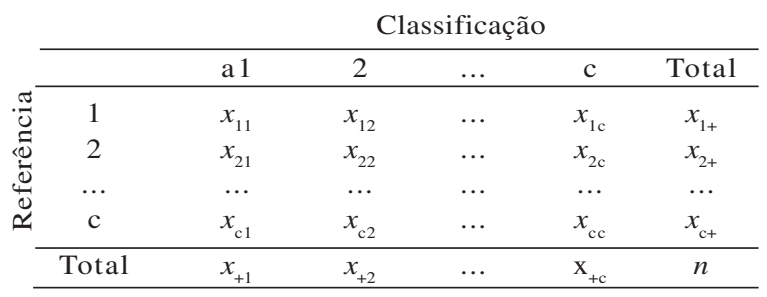

do interpolador Anudem versão 5.2, com destaque para a imposição da rede de drenagem, o MDEHC foi criado com uma resolução geométrica de $5 \mathrm{~m}$, passando posteriormente pelos refinamentos descritos no trabalho de Ribeiro et al. (2005). Em seguida, delimitou-se a área de drenagem da sub-bacia, utilizando a função Watershed do módulo Spatial Analyst do ArcGIS, cujo limite obtido foi, então, utilizado para recortar os dados originais.

\section{Delimitação das Áreas de Preservação Permanente (APPs)}

As categorias de APPs utilizadas neste trabalho foram mapeadas conforme disposto nos artigos $2^{\circ} \mathrm{e}$ 3o da Resolução n 303/02 do CONAMA. Segundo a metodologia desenvolvida por Ribeiro et al. (2002, 2005) para delimitação automática dessas áreas, as categorias utilizadas neste estudo denominaram-se: APP-1 (terço superior dos morros), APP-2 (entorno das nascentes e suas áreas de contribuição), APP-3 (faixa marginal ao longo dos cursos d'água), APP-4 (terço superior da bacia, ao longo das linhas de cumeada) e APP-5 (encostas com declividades superiores a $45^{\circ}$ ).

Para a categoria APP-1, primeiramente identificaramse a base e topo de cada elevação, respeitando os limites de declividade mínima de $30 \%$ para encostas de alturas entre $50 \mathrm{~m}$ e $300 \mathrm{~m}$. A inversão do relevo, combinada com a eliminação das células da hidrografia do MDEHC, buscou garantir que as depressões situadas sobre estas não fossem identificadas como topos. Desse modo, identificaram-se os topos dos morros e montanhas e as respectivas bases dessas elevações. Os morros cujos topos se situaram a uma distância de até $500 \mathrm{~m}$ foram agrupados, conforme determina a lei. A altura de cada morro e montanha foi obtida pela identificação da amplitude dos valores de altitude das células do MDHEC associadas a cada elevação.

A delimitação das APPs denominadas APP-2 foi obtida pela delimitação de um círculo com raio de $50 \mathrm{~m}$ ao redor das nascentes, superposto às respectivas áreas de contribuição. As APPs de faixa marginal ao longo dos cursos d'água, denominadas APP-3, foram delimitadas conforme uma série de procedimentos. Inicialmente, num ambiente vetorial, os limites das planícies de inundação foram definidos com base no perfil do relevo obtido em seções transversais adequadamente distribuídas ao longo da hidrografia (ACKERMAN et al., 2000). A malha para toda a rede hidrográfica foi obtida pelo 
comprimento de cada seção transversal, atribuindo o mesmo número de seções para cada segmento da hidrografia. A altimetria ao longo de cada seção transversal foi gerada por meio dos respectivos MDEHCs. A obtenção dos valores das cotas de cheia considerou a área de drenagem à montante de cada célula da hidrografia como variável independente, na interpolação linear efetuada entre a cota máxima de inundação na foz da sub-bacia e as cotas máximas de inundação nas nascentes.

Os valores da largura da planície foram determinados de acordo com a Resolução 303/02 do CONAMA ou com a legislação estadual, quando essa foi mais rigorosa, para posterior geração de um grid pontual para cada largura da faixa de proteção marginal. O resultado obtido foi convertido para um conjunto de pontos com as respectivas tabelas de atributos de valores de larguras. Um conjunto de círculos foi criado com origem em cada ponto situado ao longo das bordas das planícies, cujos raios eram iguais à respectiva largura da faixa de proteção. Desse modo, por meio das ferramentas de rasterização, o novo conjunto de polígonos foi utilizado para a criação do grid de identificação das APPs ao longo dos cursos d'água, que posteriormente foi sobreposto ao grid gerado das planícies de inundação.

De acordo com Ribeiro et al. (2005), a determinação das APPs nas linhas de cumeadas tem por base a bacia contribuinte de cada segmento da hidrografia. Assim, para delimitação das categorias denominadas APP-4, primeiramente identificou-se a altura de cada morro com o cume de menor altitude e calculou-se a cota da curva de nível associada ao seu terço superior. A linha de cumeada foi seccionada em segmentos de $1 \mathrm{~km}$, tendo por origem o cume mais baixo, recalculando-se a cota do terço superior da encosta para cada um desses segmentos. Ao final, obteve-se um grid com as áreas de proteção ao longo das linhas de cumeada.

A categoria de APP-5 foi obtida a partir da reclassificação do grid de declividades derivado do MDEHC.

\section{Análise de conflito de uso da terra nas APPs}

Para o mapeamento e quantificação dos conflitos de uso da terra em APPs, utilizou-se a sobreposição de mapas, procedimento executado no módulo Spatial Analyst do ArcGIS. Objetivou-se, com isso, diferenciar as seguintes classes de uso e ocupação da terra na classificação supervisionada da imagem do sensor ETM+/ LANDSAT 7: Floresta Estacional Semidecidual, Cerrado e Agropecuária, em situações de pleno atendimento e de conflito com a legislação vigente.

\section{RESULTADOS E DISCUSSÃO}

A classificação de uso e ocupação da terra para a área de estudo, com base na imagem do sensor ETM+/ LANDSAT 7, é apresentada na Figura 2. A classe Floresta Estacional Semidecidual foi a menos representativa, ocupando apenas $12,3 \%$ da área total da sub-bacia; já a classe Cerrado ocupou 52,6\%. AAgropecuária ateve-se à ocupação de 35,1\% da sub-bacia. O índice Kappa obtido para tais classes foi 0,64 . Tal valor se situa na faixa "Muito bom" para classificação da imagem

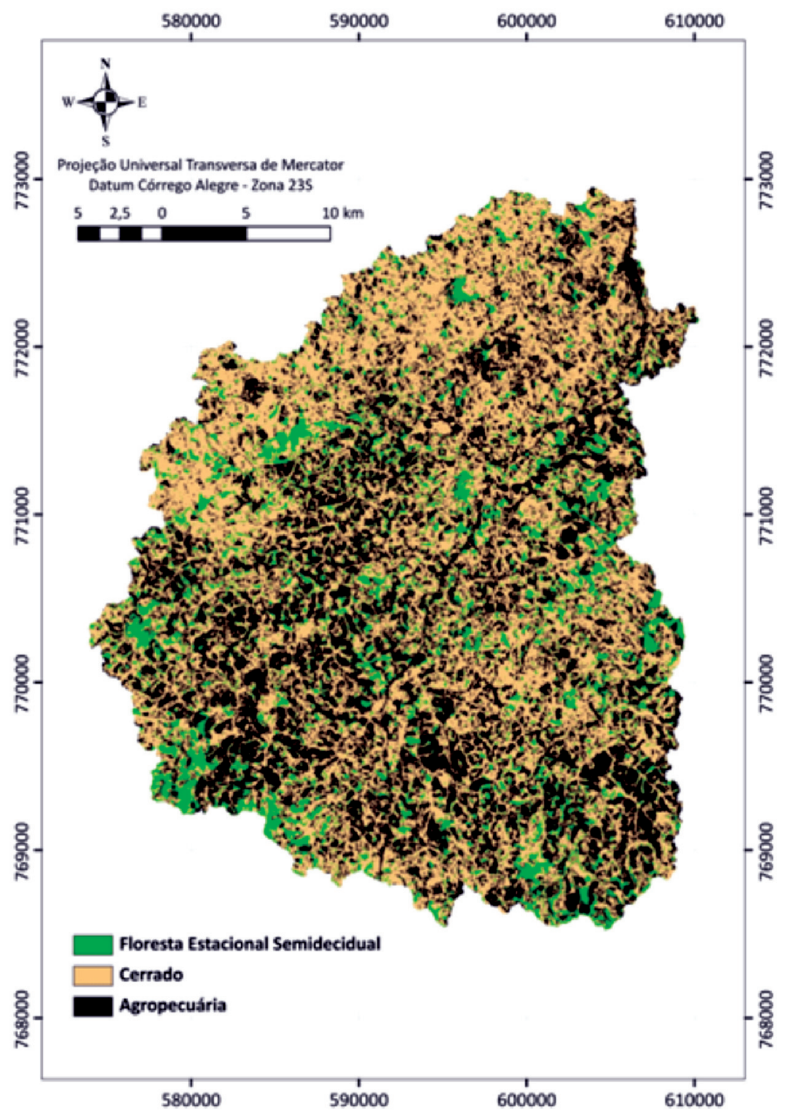

Figura 2 - Mapa de uso e ocupação da terra da sub-bacia hidrográfica do rio Camapuã/Brumado, Minas Gerais.

Figure 2-Map of land use/land cover for the study area, Minas Gerais.

Revista Árvore, Viçosa-MG, v.36, n.4, p.759-766, 2012

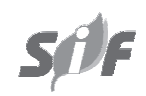


$(0,6 \leq \mathrm{K} \leq 0,8)$, segundo Foody (1992). Esse estimador de acerto considera a proporção de amostras corretamente classificadas, indicando a acurácia dos mapas gerados, a partir de sua matriz de erros (OLIVEIRA et al., 2008).

Todas as APPs da sub-bacia encontram-se distintamente representadas na Figura 3. Essas áreas ocupavam $63.095,0$ ha $(57,0 \%)$ da área total da região de estudo (110.711,9 ha). O percentual de APPs para esta sub-bacia está coerente com os valores encontrados por outros autores em diversos estudos a respeito da espacialização de APPs. Nascimento et al. (2005), mapeando as áreas de preservação permanente da bacia hidrográfica do rio Alegre, ES, concluíram que $46 \%$ da área da bacia deveria ser legalmente protegida. Em estudo semelhante, desenvolvido por Oliveira (2002) na microbacia do Paraíso, Viçosa, MG, quantificaramse $52 \%$ da área como de preservação permanente. A categoria APP-4 (terço superior da bacia ao longo das linhas de cumeada) teve maior representação na área de estudo, correspondendo a 52,6\% das áreas legalmente protegidas, enquanto as categorias APP-5 e APP-1 (encostas com declividade superior a $45^{\circ}$ e terço superior de morros, respectivamente) apresentaram menor participação entre as categorias mapeadas, somando $0,4 \%$ do total de APPs. As áreas de proteção restante - margens dos cursos d’água (APP-3) e nascentes e áreas de contribuição (APP-2) - correspondem a 31,4\% e $15,6 \%$ da área de uso legal da sub-bacia, respectivamente.

A soma das áreas individuais das categorias de APPs mapeadas (75.402,7 ha) difere em 12.307,7 ha da área coberta por APPs nessa sub-bacia (63.095,0 ha). Essa diferença refere-se às regiões onde há sobreposições das categorias de APPs, ocorrendo principalmente entre as APPs localizadas ao longo das linhas de cumeada, nas nascentes e suas áreas de contribuição e ao longo dos cursos d'água. Essa conexão natural proporciona a formação de corredores ecológicos, criando uma rede de áreas protegidas e interconectadas. Os corredores ecológicos constituem um meio eficiente de minimizar os efeitos deletérios impostos às populações da fauna e flora pela fragmentação de hábitats.

A análise dos resultados permitiu a distinção de três situações básicas de uso e ocupação da terra na sub-bacia: 1) áreas de uso legal, 2) APPs conservadas e 3 ) áreas em conflito de uso da terra (Figura 4). Do total das APP's mapeadas, $41.155,7$ ha $(65,2 \%)$ estão efetivamente protegidos por fragmentos florestais dos domínios vegetacionais Floresta Atlântica (Floresta Estacional Semidecidual) e Cerrado. Considerando as Áreas de Preservação Permanente efetivamente respeitadas, $42,55 \%$ situavam-se no terço superior da bacia, ao longo das linhas de cumeada; $39,44 \%$ ao longo dos cursos d'água; $17,51 \%$ nas nascentes e suas áreas de contribuição; e apenas $0,19 \%$ localizavam-se no terço superior de morros e em áreas com declividades superiores a $45^{\circ}$.

As áreas de uso legal foram quantificadas em 47.616,9 ha, representando $43,0 \%$ da área total da sub-bacia estudada. A classe Agropecuária ocupa 16.882,6 ha $(35,5 \%)$ da área de uso legal, conforme ilustrado na Tabela 2. Apesar da existência de 21.939,3 ha em conflito de uso da terra, foram mapeados $30.734,3$ ha $(64,5 \%$

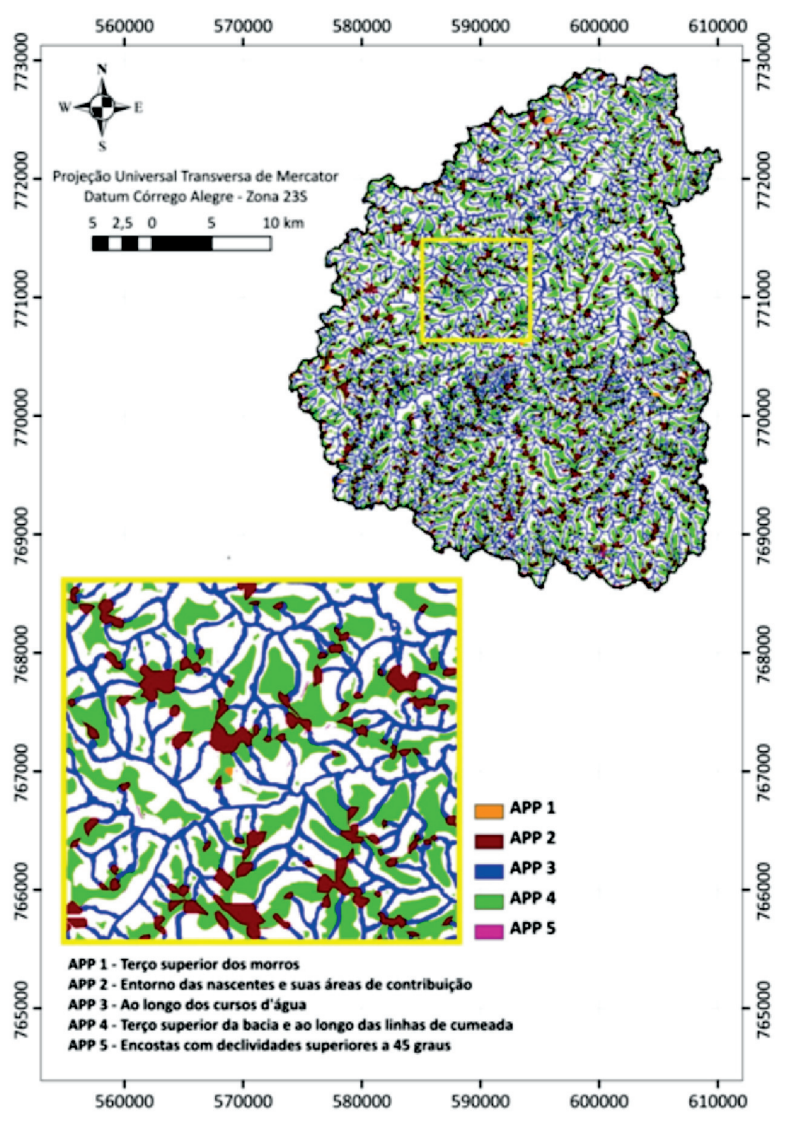

Figura 3-Categorias deAPPs delimitadas na sub-bacia hidrográfica do rio Camapuã/Brumado, Minas Gerais.

Figure 3 - Visual depiction of protected areas categories, as set by the Brazilian Forest Code, within the Camapuã/Brumado watershed. 
Tabela 2 - Descrição do uso da terra nas áreas de uso legal na sub-bacia hidrográfica do rio Camapuã/Brumado, Minas Gerais. Table 2 -Land use/land cover classes in areas where exploration is allowed.

\begin{tabular}{lrcl}
\hline Uso da terra em área de uso legal & \multicolumn{1}{c}{ Área (ha) } & Área (\%) & Caracterização \\
\hline Floresta Estacional Semidecidual & $4.865,8$ & 10,2 & Passíveis de desmatamento \\
Cerrado remanescente & $25.868,5$ & 54,3 & Passíveis de desmatamento \\
Agropecuária & $16.882,6$ & 35,5 & Em conformidade com o uso da terra \\
\hline Total & $47.616,9$ & 100,0 & \\
\hline
\end{tabular}

da área de uso legal), constituídos de fragmentos florestais em áreas passíveis de serem utilizadas pelo proprietário da terra. Por fim, gerou-se um mapa contendo as áreas de conflito de uso da terra para a região analisada (Figura 4).

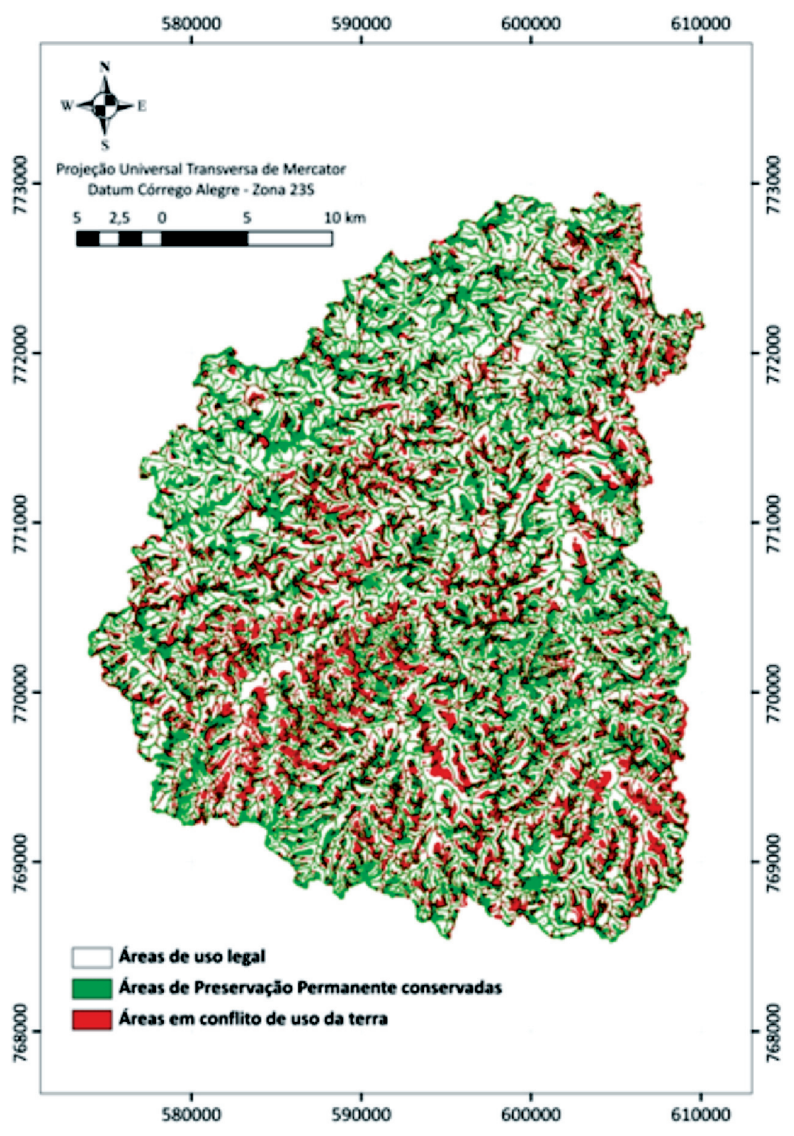

Figura 4 - Mapa dos conflitos de uso da terra na sub-bacia hidrográfica do rio Camapuã/Brumado, Minas Gerais.

Figure 4-Map of legal and ilegal use and occupation of land within the Camapuã/Brumado watershed.

\section{CONCLUSÕES}

O uso do sensor ETM+/LANDSAT foi adequado para mapear as três classes de uso e ocupação da terra - Floresta Estacional Semidecidual, Cerrado e Agropecuária - na área de estudo.

Analisando a distribuição espacial das APPs delimitadas para a sub-bacia hidrográfica do rio Camapuã/ Brumado, percebeu-se claramente que elas resultaram na formação natural de corredores ecológicos, conectando os fragmentos florestais remanescentes. Se, por um lado, parcela considerável $(\sim 36 \%)$ dessas áreas especialmente protegidas encontrava-se atualmente sob exploração agropecuária, numa clara violação do Código Florestal em vigor, por outro áreas sem qualquer impedimento legal à sua exploração apresentavam-se cobertas por formações florestais nativas.

Essas situações extremas e aparentemente contraditórias corroboram a hipótese de que a falta de conhecimento do proprietário da terra - e mais ainda dos órgãos de fiscalização - a respeito da correta localização das APPs dentro de sua propriedade é a principal causa do descumprimento da lei. A adoção em larga escala do mapeamento automático das APPs poderá, sem dúvida, contribuir para minimizar os conflitos de uso da terra e evitar a degradação dos fragmentos florestais remanescentes.

\section{AGRADECIMENTOS}

Ao CNPq e à FAPEMIG, pelo apoio financeiro ao desenvolvimento desta pesquisa.

\section{REFERÊNCIAS}

ACKERMAN, C. T.; EVANS, T. A.; BRUNNER, G. W. Paper 8 - HEC - GeoRAS: linking GIS to hydraulic analysis using Arc/ INFO and HEC-RAS. In: MAIDMENT, D.; DJOKIC, D. (Eds). Redlands: Environmental Systems Research Institute, 2000. p.155-176.

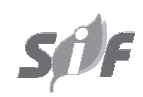

Revista Árvore, Viçosa-MG, v.36, n.4, p.759-766, 2012 
CALABRIA, C. A. Particularidades da aplicação da legislação florestal brasileira na Zona da Mata mineira: áreas de preservação permanente e reserva legal. 2004. 132f. Dissertação (Mestrado em Ciência Florestal) Universidade Federal de Viçosa, Viçosa, MG 2004.

ENVIRONMENTALSYSTEMS RESEARCH INSTITUTE - ESRI. ArcGIS Professional GIS for the desktop, versão $9.3 \mathrm{CA}$., 2008.

FOODY, G. M. On the compensation for chance agreement in image classification accuracy assessment. Photogrammetric Engineering and Remote Sensing, v.58, n.10, p.1459-1460, 1992.

INSTITUTO BRASILEIRO DE GEOGRAFIA E ESTATÍSTICA - IBGE. Mapa de vegetação

do Brasil, escala 1:5.000.000, Projeção Policônica, M.C. 54º W. Gr. Brasília, DF: 2004.

LILLESAND, T. M.; KIEFER. R. W. Remote sensing and image interpretation. New York: John Wiley \& Sons, 2001. 820p.

NASCIMENTO, M. C. et al. Uso do geoprocessamento na identificação de conflito de uso da terra em áreas de preservação permanente na Bacia Hidrográfica do Rio Alegre, Espírito Santo. Ciência Florestal, v. 15, n. 2, p. 207-220, 2005.

OLIVEIRA, F. S. et al. Identificação de conflito de uso da terra em áreas de preservação permanente no entorno do Parque Nacional do Caparaó, Estado de Minas Gerais. Revista Árvore, v.32, n.5, p.899-908, 2008.

Oliveira, M. J. Proposta metodológica para delimitação automática de Áreas de Preservação Permanente em topos de morro e em linha de cumeada. 2002. 53f. Dissertação (Mestrado em Ciência Florestal) Universidade Federal de Viçosa, Viçosa, MG, 2002.
OLIVEIRA FILHO, A. T. Estudos ecológicos da vegetação como subsídios para programas de revegetação com espécies nativas: uma proposta metodológica. Revista Cerne, v.1, n.1, p.64-72, 1994.

PIRES, A. M. Z. C. R.; SANTOS, J. E.; PIRES, J. S. R. Elaboração de um banco de dados digitais georreferenciados para caracterização ambiental de unidade de conservação. In: SEMINÁRIO REGIONAL DE ECOLOGIA, 8., 1998, São Carlos. Anais. São Carlos: 1998. p.585-598.

RIBEIRO, C. A. A. S. et al. O desafio da delimitação de área de preservação permanente. Revista Árvore. v.29, n.2, p.203-212, 2005.

RIBEIRO, C. A. A. S. et al. Delimitação automática de áreas de preservação permanente em topos de morros e em linhas de cumeada: Metodologia e estudo de caso. In: SEMINÁRIO DE ATUALIZAÇÃO EM SENSORIAMENTO REMOTO E SISTEMAS DE INFORMAÇÕES GEOGRÁFICAS APLICADAS À ENGENHARIA FLORESTAL, 5., 2002, Curitiba. Anais... Curitiba: 2002. p.7-18

TONIAL, T. M. et al. Caracterização preliminar de áreas de vegetação em microbacias da região noroeste do estado do Rio Grande do Sul.

Revista de Pesquisa e Pós-

Graduação, v.1, n.1, p. 107-115, 2000. Disponível em < http:// http://www.uri.br/ publicaonline/revistas/artigos/7.pdf $>$. Acesso em: 30 jan. de 2009.

VALLOUREC/SUMITOMO TUBOS DO BRASIL.

Estudo de Impacto ambiental -

Complexo siderúrgico Jaceaba. Belo Horizonte; 2007. 440p. 